\title{
Campanhas educativas de controle do tabagismo: do vício moral ao estilo de vida saudável
}

\author{
Educational smoking control campaigns: from moral addiction to healthy \\ lifestyle
}

\section{Campañas educativas de control de fumadores: de la adicción moral al estilo de vida saludable}

Ester Cristina Machado Ruas ${ }^{1,2, a}$

crisruastb@gmail.com | http://orcid.org/o00o-0001-6170-4149

Ana Paula Goulart Ribeiro ${ }^{3, b}$

goulartap@gmail.com | https://orcid.org/oooo-0002-9341-4629

${ }^{1}$ Universidade Federal Fluminense. Rio de Janeiro, RJ, Brasil.

2 Fundação Oswaldo Cruz, Instituto de Comunicação e Informação Científica e Tecnológica em Saúde. Rio de Janeiro, RJ, Brasil.

3 Universidade Federal do Rio de Janeiro, Escola de Comunicação. Rio de Janeiro, RJ, Brasil.

a Doutorado em Informação e Comunicação em Saúde pela Fundação Oswaldo Cruz.

${ }^{b}$ Doutorado em Comunicação e Cultura pela Universidade Federal do Rio de Janeiro.

\section{Resumo}

Este artigo é resultado do trabalho de pesquisa sobre a produção das campanhas antitabagistas de governo e sobre a forma com que foram apropriados pela população. Nosso objetivo foi avaliar como essas campanhas foram pensadas em relação aos princípios de comunicação e saúde pressupostos pelo Sistema Único de Saúde. A expectativa foi problematizar a questão numa perspectiva interdisciplinar. Analisamos documentos a partir dos preceitos teóricos e metodológicos da Semiologia dos Discursos Sociais. Concluiu-se que foram criadas campanhas alarmistas, pautadas na imputação do medo e na vigília moral, que acabaram por se distanciar da ideia de uma comunicação em saúde pública dialógica, informativa e participativa.

Palavras-chave: Campanha; Tabagismo; Saúde; Comunicação; Vigília moral. 


\begin{abstract}
This article is the result of a research on the use of the concept of aversion in the production of government anti-smoking campaigns and how they were appropriated by the population. Our objective was to evaluate how these campaigns were conceived in relation to the principles of communication and health presupposed by the Unified Health System. The expectation was to problematize the issue from an interdisciplinary perspective. We analyze documents from the theoretical and methodological precepts of Semiology of Social Discourses. It was concluded that alarmist campaigns were created, based on the imputation of fear and on moral vigilance, which eventually distanced these actions from the principles of communication in dialogic, informative and participatory public health.
\end{abstract}

Keywords: Campaign; Smoking; Health; Communication; Moral vigil.

\title{
Resumen
}

Este artículo es el resultado del trabajo de investigación sobre la utilización del concepto de aversión en la producción de las campañas antitabaco de gobierno y sobre la forma en que fueron apropiados por la población. Nuestro objetivo fue evaluar cómo estas campañas fueron pensadas en relación a los principios de comunicación y salud presupuestados por el Sistema Único de Salud. La expectativa fue problematizar la cuestión desde una perspectiva interdisciplinaria. Analizamos documentos a partir de los preceptos teóricos y metodológicos de la Semiología de los Discursos Sociales. Se concluyó que se crearon campañas alarmistas, pautadas en la imputación del miedo y en la vigilia moral, que acabaron por distanciarse de la idea de una comunicación en salud pública dialógica, informativa y participativa.

Palabras clave: Campaña; Fumar; Salud; Comunicación; Vigilia moral.

Contribuição dos autores:

Concepção e desenho do estudo: Ester Cristina Machado Ruas e Ana Paula Goulart Ribeiro;

Aquisição, análise ou interpretação dos dados: Ester Cristina Machado Ruas;

Redação do manuscrito: Ester Cristina Machado Ruas;

Revisão crítica do conteúdo intelectual: :Ester Cristina Machado Ruas e Ana Paula Goulart Ribeiro.

Declaração de conflito de interesses: não há.

Fontes de financiamento: não houve.

Considerações éticas: não há.

Agradecimentos/Contribuições adicionais: não há.

Histórico do artigo: submetido: 10 out. 2018 | aceito: 17 out. 2019 | publicado: 20 dez. 2019.

Apresentação anterior: o artigo apresenta os resultados da tese de doutorado "As Advertências Sanitárias no maço de cigarros: política pública e prática comunicativa do Sistema Único de Saúde", defendida no Programa de Pós-graduação em Informação e Comunicação em Saúde do Instituto de Comunicação e Informação Científica e Tecnológica em Saúde da Fiocruz, em 2016.

Licença CC BY-NC atribuição não comercial. Com essa licença é permitido acessar, baixar (download), copiar, imprimir, compartilhar, reutilizar e distribuir os artigos, desde que para uso não comercial e com a citação da fonte, conferindo os devidos créditos de autoria e menção à Reciis. Nesses casos, nenhuma permissão é necessária por parte dos autores ou dos editores. 


\section{Introdução}

As campanhas publicitárias durante a Segunda Guerra, e mesmo no período da Guerra Fria, eram influenciadas por teorias da comunicação social de natureza funcionalista. A principal delas, a chamada Mass Communication Research, foi desenvolvida por investigadores norte-americanos que buscavam entender os efeitos dos meios sobre a sociedade de massa. Sobretudo os representantes das primeiras gerações de pesquisadores acreditavam na capacidade de uma mensagem suscitar uma resposta condicionada. Como diria Lasswell, pensava-se na "imagem de uma massa atomizada de milhões de eleitores, espectadores etc., que recebiam as mensagens e a configuração da mensagem como um estímulo direto e poderoso que podia dar origem a respostas imediatas" ${ }^{1}$.

As práticas de difusão do tabaco pela publicidade foram baseadas nessa perspectiva teórica que entendia os meios a partir dos seus efeitos. O tabaco passou a ser divulgado por meio de dispositivos que atingiam o indivíduo num grupo social, persuadindo-o a pertencer a uma coletividade que almejava a mudança, o prazer e o sucesso. Quem não se lembra do slogan 'Hollywood, o sucesso!'?

Com imagens do mundo do esporte, essa marca de cigarro foi lançada em 1931 pela companhia de tabaco Souza Cruz, com o objetivo de vincular seu nome ao sucesso e ao prazer. Os reclames da marca Hollywood ditaram um estilo de vida que atingiu a juventude. A agência de publicidade Grant, segundo Pinho $^{2}$, adotou a fórmula que se tornou um modelo a ser seguido por longo tempo na comunicação da marca, o de promover a associação do produto com um esporte de ação.

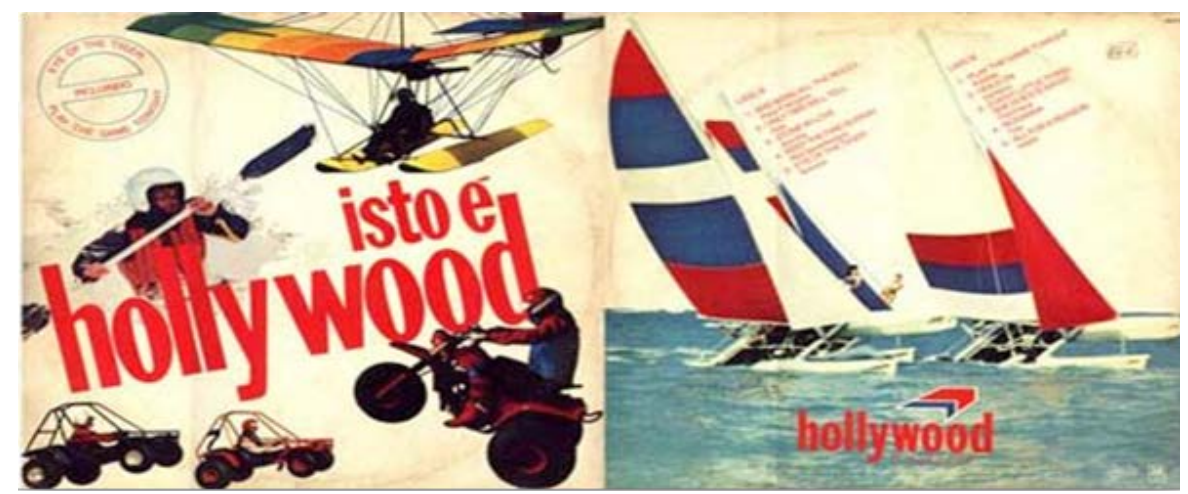

Figura 1 - Anúncio de Cigarros Hollywood nos anos 1980

Fonte: Multi-midia. ${ }^{3}$

Para Pinho, a estratégia de investir em comunicação mercadológica garantiu uma poderosa imagem de marca "desenvolvendo mensagens que levam em conta os valores, gosto e posição social dos consumidores".

Hollywood talvez seja a evidência mais clara da relação íntima entre cinema americano e consumo de cigarros ${ }^{4}$. Em 1949, a marca podia ser vista nos lábios glamorosos dos artistas nos filmes da indústria cinematográfica de Hollywood. 


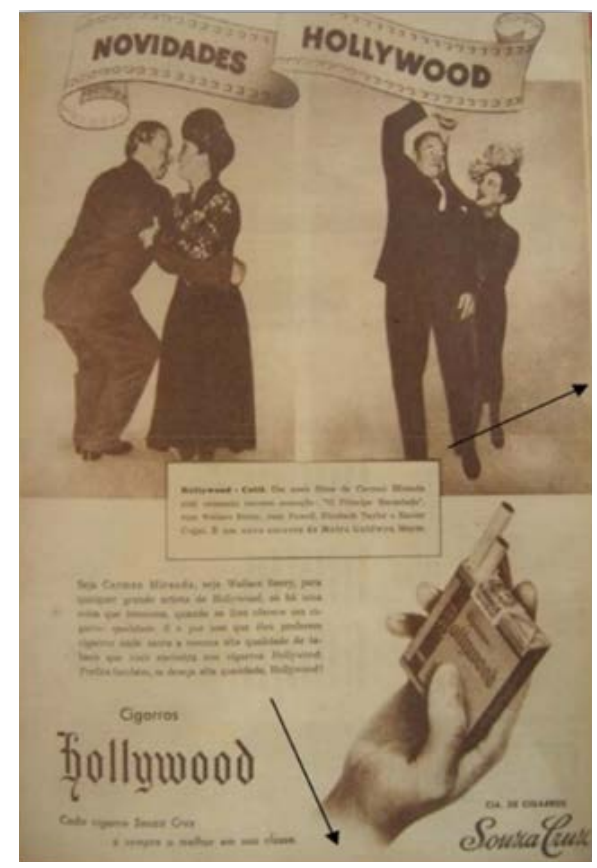

Figura 2 - Anúncio de Cigarros Hollywood, veiculado na revista O Cruzeiro Fonte: O Cruzeiro. ${ }^{5}$

Outra imagem que marcou época foi a do personagem usado para divulgar a marca de cigarros Marlboro: 'o cowboy de Marlboro'. A campanha criada pela Leo Burnett Worldwide, agência de publicidade estadunidense coordenada por Jack Landry, conhecido publicitário da Philip Morris, envolveu, a partir de 1995, garotos-propaganda cowboys numa tentativa de levar o público masculino a consumir cigarros com filtro, considerados femininos na época. Para Pinho foi "a imagem certa para capturar a fantasia da juventude, um símbolo perfeito de independência e rebeldia individualista".

O ator Eric Lawson, que, junto com outros três 'Marlboro Man', foi reconhecido como o homem símbolo da marca norte-americana Marlboro entre 1978 e 1981, morreu aos 72 anos, em 2014, em função de complicações vinculadas ao tabagismo.

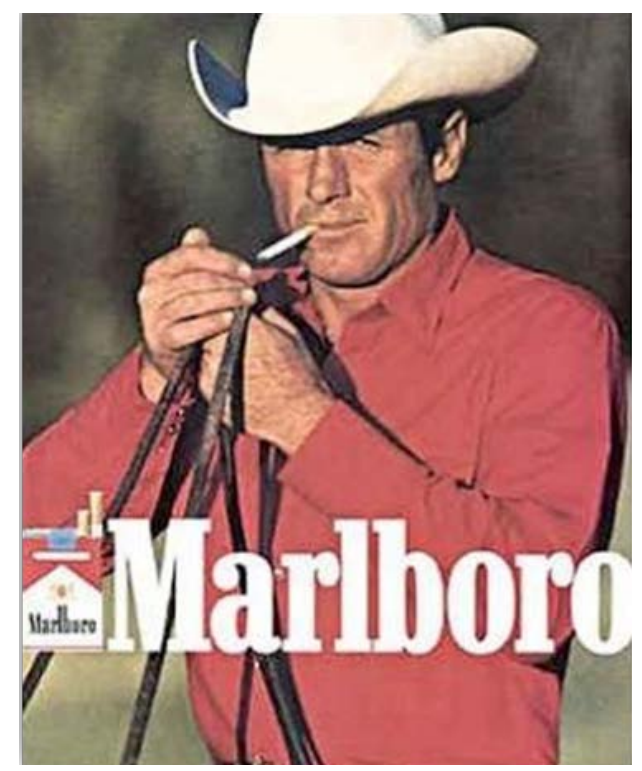

Figura 3 - Ator Eric Lawson, 'Marlboro Man' Fonte: The Sun. ${ }^{6}$ 
O tabaco ultrapassa o seu uso milenar, ocorrido em quase todas as culturas humanas, segundo Carneiro7, como parte indispensável dos ritos de sociabilidade, cura, devoção, consolo e prazer para se tornar um sinal de status, ritual de iniciação à vida adulta e prova de independência, além de ser um dos principais ramos do comércio de cultivo e exportação.

A consequência do crescimento do consumo de cigarros nos anos 1950 foi o alarmante aumento da incidência de câncer de pulmão nos homens. O hábito de fumar resultou em uma alteração epidemiológica com a revelação científica dos pesquisadores Wynder e Graham ${ }^{8}$ e Doll e Hill’, que estabeleceu a relação entre o tabaco e um tipo de câncer de pulmão.

Passado mais de meio século após essa revelação científica, é previsto que até o ano de 2030 o câncer afetará mais de 22 milhões de pessoas em todo o mundo, com mais de 17 milhões morrendo da doença ${ }^{10}$, e o tabaco é um fator que pode aumentar seriamente o risco de câncer. Tal conclusão foi capaz de alterar os sentidos de saúde, glamour e prazer que aproximavam o sujeito do cigarro para o distanciamento do produto, agora tóxico, provocador do risco de vida e causador de doença. $\mathrm{O}$ alcance e a difusão desse achado científico transformaram a percepção da sociedade sobre o cigarro mostrando os malefícios causados à saúde do indivíduo e da coletividade. Siddhartha escreveu no livro biográfico sobre o câncer O Imperador de Todos os Males: “[...] no turbulento século de 1850 a 1950, o mundo ofereceu conflitos, atomização e desorientação. O cigarro ofereceu o lenitivo oposto: camaradagem, senso de pertencer a uma coletividade e a familiaridade do hábito. Se o câncer é o produto quintessencial da modernidade, assim também é com sua principal causa evitável: o tabaco"11.

Na segunda metade do século XX, pesquisadores defenderam que o consumo abusivo do tabaco era, na verdade, questão de saúde pública. O tabagismo foi, assim, reconhecido como uma doença crônica gerada pela dependência da nicotina. Governos de diversos países tomaram consciência do problema, promulgando regulações e leis de âmbito nacional de combate ao tabagismo e desenvolvendo campanhas educativas.

O cigarro, entretanto, continua sendo a principal causa de morte evitável em todo o mundo. Segundo o último relatório Global Tobacco Epidemic ${ }^{12}$, o cigarro causa seis milhões de mortes no mundo por ano, a maioria em países de baixa e média renda. No documento, a OMS alerta que, se essa tendência se mantiver, o número de mortes ligadas ao fumo deve aumentar para oito milhões ao ano em 2030, e que $80 \%$ desses óbitos deverão acontecer nos países mais pobres.

O documento aponta o tabaco como o culpado pela epidemia de doenças não transmissíveis que o mundo vive hoje, e junto a ele, no banco dos réus, coloca o marketing agressivo de grandes indústrias de tabaco. O relatório mostrou que medidas de restrição ao cigarro - como proibição da publicidade e realização de campanhas antitabagistas - atingem hoje uma em cada três pessoas no mundo, o equivalente a 2,3 bilhões de indivíduos. São 400 milhões de pessoas a mais em comparação a dez anos atrás.

Os Estados Unidos iniciaram uma verdadeira operação contra o câncer. Pesquisas, campanhas publicitárias, formação de grupos para lobby político, enfim, todos os meios e coalizações foram utilizados para o ataque nacional ao câncer. A ideia, como mostrou Siddhartha era 'transformar o panorama da pesquisa médica nos Estados Unidos numa escala sem precedentes"1. Para o autor, "uma doença precisa ser transformada politicamente antes de ser transformada cientificamente"11.

Tal medida fez declinar o mercado e os lucros sobre a venda do cigarro nos EUA. Em consequência, a indústria tabaqueira buscou novos mercados nos países em desenvolvimento. Esse deslocamento de estratégia elevou proporcionalmente o número de fumantes nesses países, inclusive no Brasil, e, por conseguinte, o número de mortes por câncer no pulmão no país.

Para proteger a saúde da população dos danos do uso do tabaco, o Estado brasileiro implementou políticas públicas visando à promoção, prevenção e assistência relacionadas ao tabagismo. Reconheceu, assim, os malefícios causados pelo hábito de fumar individualmente ou em grupos sociais e a necessidade de criar estratégias para promover a mudança de crenças, atitudes e comportamentos. Entendeu-se que o 
tabagismo não era um vício moral de responsabilidade exclusiva do indivíduo e que cabia ao Estado regular a venda e a propaganda de tabaco.

Nesse sentido, o objetivo desse ensaio é refletir sobre as condições históricas, políticas e sociais de circulação das campanhas antitabagistas do governo brasileiro. Na leitura dos documentos que narram a história imagética das campanhas educativas de controle do tabagismo, buscamos compreender os processos que levaram à utilização do conceito de aversão e seu significado para os campos de conhecimento da saúde e da comunicação.

Analisamos documentos existentes em acervos textuais, bibliográficos eimagéticos, como os que se encontram no banco de imagens Câncer - atores, cenários e políticas públicas, da Casa de Oswaldo Cruz, da Fundação Oswaldo Cruz. Ali, é possível encontrar parte significativa do material gráfico usado em ações de educação em saúde realizadas por instituições públicas com vistas ao controle do câncer e do tabagismo no Brasil.

O acervo iconográfico foi formado por imagens obtidas no Instituto Nacional de Câncer José Alencar Gomes da Silva, no Museu de Saúde Pública de São Paulo, e em material cedido pela família Kroeff. São, principalmente, fotografias, cartazes, folders e panfletos utilizados em campanhas nacionais produzidas a partir da década de 1940 e, sobretudo, nos anos de 1980. Examinando esse acervo, foi possível fazer uma leitura mais apurada e perceber transformações e mudanças de paradigmas nas práticas comunicativas. A análise levou em conta os contextos sociais e culturais.

A história começa com as primeiras campanhas de controle do tabagismo, a partir de 1940, que se baseiam nas evidências sanitárias associadas ao risco do tabagismo. O resultado foi a produção de mensagens que buscavam incutir na consciência pública a hipérbole da proteção, culpando e responsabilizando o fumante em si mesmo e dentro do corpo social. Essas imagens expressam sentidos de terror e medo, perda da saúde e morte. Foi um alarmismo reverberado pelas mídias e autoridades da saúde. Na sequência, já nos anos de 1960, o alarde público que influenciou as campanhas antitabagistas soma-se ao medo, o diagnóstico e o tratamento do doente, contribuindo para criar um ambiente social que enfatizava a visão curativa e assistencial.

A partir dos anos 1980, associado ao debate do estilo de vida como estratégia de saúde pública, torna-se consenso que vida saudável promove qualidade na existência do ser humano. Isso criou uma mudança de paradigma nas campanhas do Ministério da Saúde. As narrativas de perda da saúde começaram a dar lugar ao ganho de qualidade de vida com a cessação do hábito de fumar. As campanhas, como canal de comunicação mediador entre o campo da saúde e a sociedade, passaram a se pautar pela prevenção e pela promoção da saúde como modos de evitar a doença.

\section{No início, a doença como metáfora}

As primeiras ações educativas que deram visibilidade ao câncer são da década de 1920. Alguns médicos, preocupados com a ampliação dos índices da doença, começaram a elaborar pequenos panfletos orientando sobre a prevenção e o diagnóstico precoce. As campanhas educativas veiculavam imagens e metáforas específicas. A mais comum era a do caranguejo, símbolo do câncer, sempre apresentado como figura aversiva que levava as vítimas à morte. Era frequente também serem usadas imagens de feridas e deformações causadas pela doença. O médico Mário Kroeff, diretor do Serviço Nacional de Câncer em 1944, acreditava que tais imagens: "em vez de afastar a população da medicina, quando apresentadas em correta medida, agiam no sentido de alertar a população sobre a doença"13 


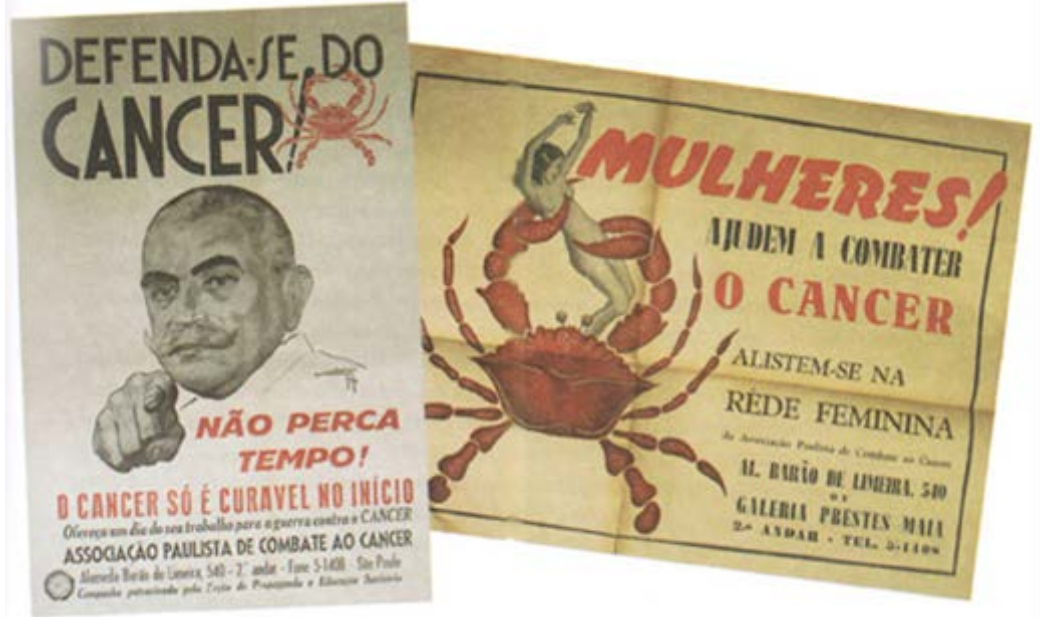

Figura 4 - Defenda-se do Câncer / Mulheres Ajudem a Combater o Câncer Fonte: Acervo Museu de Saúde Pública de São Paulo.

A difusão do controle do câncer chega ao Brasil pelas mãos da comunidade médico-científica. Profissionais como Juliano Moreira e Álvaro Ramos trataram do tema com Oswaldo Cruz, então diretor de Saúde Pública. Eles propuseram como projeto a realização de censo por meio de um inquérito entre os médicos. Os inquéritos sanitários, que passam a incluir levantamentos sobre o conhecimento da doença, serviram de base para as práticas de comunicação das instituições sanitárias que, segundo Pitta ${ }^{14}$, buscavam se ajustar às normas e prioridades epidemiológicas definidas.

Foi, no entanto, com Carlos Chagas que a comunicação como estratégia na luta contra o câncer ganhou um capítulo na Lei Sanitária do Programa do Departamento de Saúde Pública. A lei se refere à organização de propagandas contra o câncer com campanhas de educação mediante cartazes, folhetos e filmes.

A matéria do jornal Correio da Manhã de 1942, intitulada 'Luta contra o câncer na história da medicina', trata da exibição gratuita do primeiro filme nacional de longa-metragem sobre o assunto. Foi entrevistado Mário Kroeff, diretor do Serviço Nacional de Câncer, responsável pela campanha contra a doença em todo o território nacional e supervisor do filme. No ano seguinte, no mesmo jornal, uma entrevista com Kroeff divulgou o Dia Nacional de Controle do Câncer como forma de estabelecer a educação do público. O estabelecimento de datas nacionais para promoção de prevenção é uma estratégia de comunicação utilizada até hoje pelo Ministério da Saúde ${ }^{13}$.

Para Pitta, outra forte estratégia foi o uso dos meios de comunicação de massa: "o rádio e o cinema se consolidam como instrumentos de propaganda política e sua relação com os regimes totalitários. A conduta é explicada neste contexto a partir de teorias behavioristas apropriadas pelos estudos de comunicação"14. Ganham, assim, destaque as teorias funcionalistas, que estudam os efeitos diretos da propaganda e que valorizam a superestrutura e a ideologia de dominação das massas. Para Lasswell ${ }^{1}$, um dos principais representantes dessa corrente de pensamento, a comunicação - concebida a partir do modelo estímulo-resposta - teria o poder de propagar informações, difundir mensagens e convencer as massas.

Ancorado nessas teorias de comunicação de fundo behaviorista, surge, nas primeiras décadas do século XX, o sanitarismo campanhista, como afirmam Cardoso e Araujo ${ }^{15}$. Para as autoras, a difusão de medidas de higiene ocorreu por meio de práticas baseadas na ideia da comunicação como relação causal e automática entre estímulos e respostas.

Essa política de comunicação no período entre guerras foi reproduzida pelo presidente da República Getúlio Vargas, estimulado pela visão mundial da propaganda como ferramenta eficaz na gestão governamental (Lasswell ${ }^{16}$ ). O rádio tornou-se um aliado da medicina preventiva, na voz da comunidade 
científica e governamental. Especialistas nas campanhas de controle do câncer assumiram os microfones das rádios dando entrevistas, visando, assim, difundir informações e alterar hábitos da população.

Foi na rádio do Ministério da Educação que, em 1943, o Dr. Alberto Lima de Moraes Coutinho, chefe de clínica do Serviço Nacional de Câncer, falou sobre uma série de fatores que permitem o aparecimento do mal: "[...] o vício mais comum a que se entregam os homens é o fumo generalizado, que passou à categoria de hábito individual e social. Os malefícios oriundos dessa prática não são pequenos. A maioria absoluta dos cânceres de lábios, língua e laringe aparecem nos fumantes inveterados e é a razão de sua grande frequência nos homens e pouco achado nas mulheres”13.

Uma característica marcante das peças de propaganda dessa época é o uso de metáforas bélicas. A prevenção era mencionada como uma verdadeira guerra contra a doença. Eram ecos da Segunda Guerra Mundial. As peças mostravam aviões de guerra e comparavam o trabalho dos médicos (ou do organismo humano) às atividades dos soldados durante as batalhas.

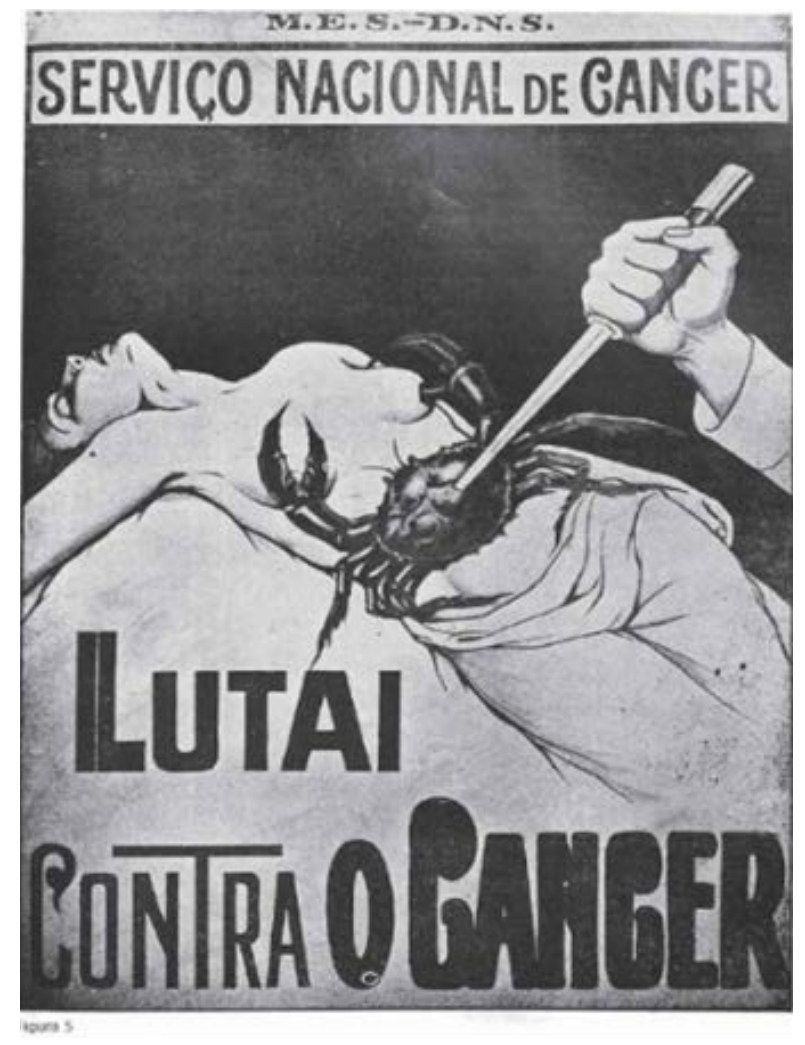

Figura 5 - Lutai Contra o Câncer

Fonte: Ministério da Saúde. ${ }^{13}$

Somava-se à metáfora do caranguejo, o cenário bélico, um alerta ou advertência representados pela "morte anunciada" ${ }^{17}$. No reforço a este clima, as mensagens e imagens eram envolvidas em branco e preto, sendo usados termos como 'luta' e 'contra' numa linha de ataque e defesa. Numa das peças produzidas pelo Serviço Nacional de Câncer (figura 5), o corpo humano é representado por meio de uma mulher e de uma mão que lhe tira a vida. 


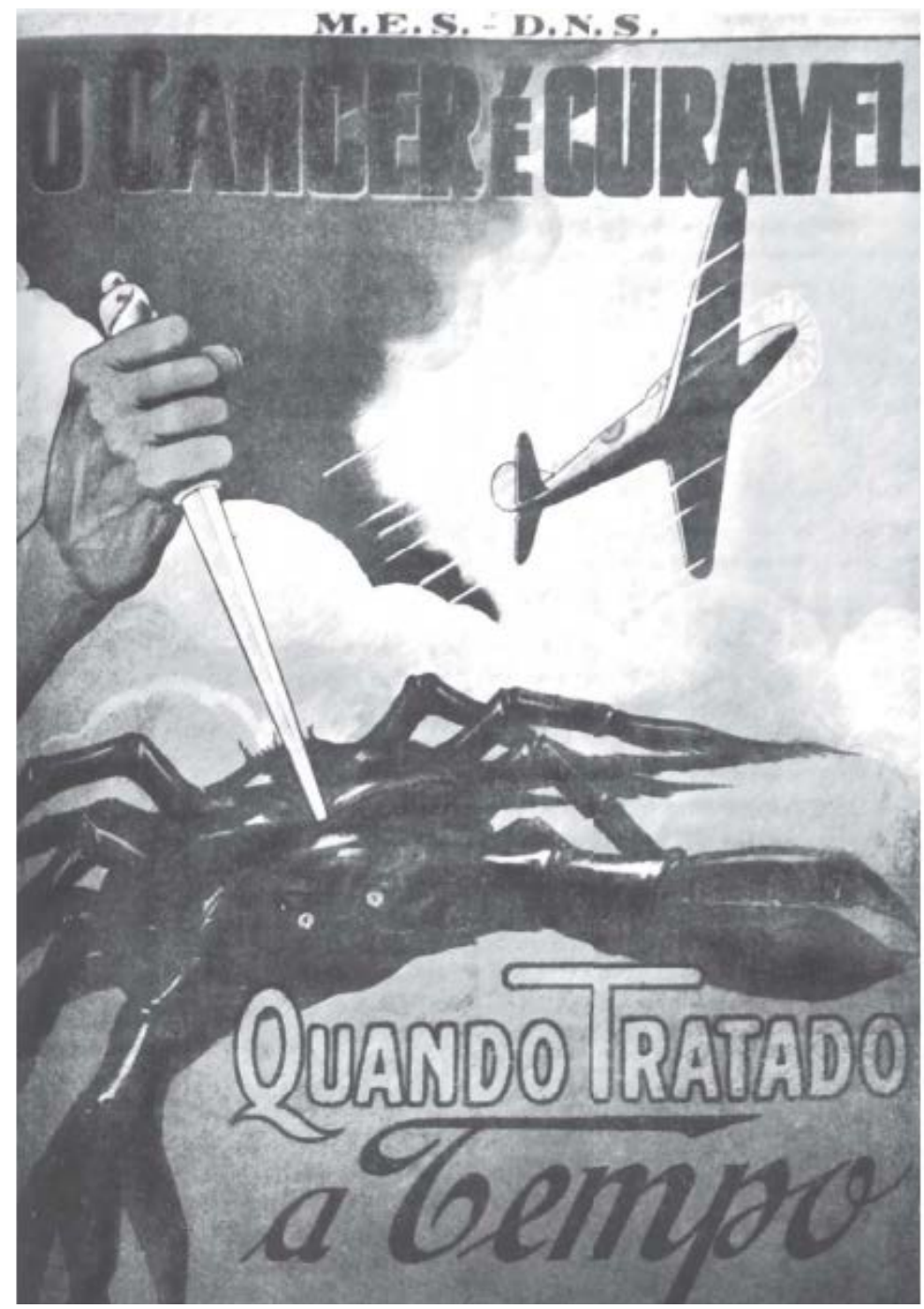

Figura 6 - O câncer é curável Fonte: Ministério da Saúde. ${ }^{13}$

Podemos interpretar o risco de morte em duas dimensões: a externa e a interna. Externa, pois pertencia ao corpo social do clima de guerra daqueles tempos, e interna por ser uma doença dentro do corpo humano; quer dizer, movimentos externos e internos geradores de conflitos. Fazemos uso das palavras da escritora Salecl apud Siddhartha"1" "a podridão, o terror - a decadência biológica e a concomitante decadência espiritual - foram levados para dentro do corpo da sociedade e, por extensão, para dentro do corpo humano".

As guerras eram riscos percebidos como terror externo à sociedade, e o cigarro passa do sentido do desejo para objeto de horror, causador de males no interior do corpo. As autoridades sanitárias governamentais, por sua vez, reforçavam por meio da propaganda de massa essa representação com imagens do "império do mal desconhecido", evidenciando a perda da saúde. O cigarro era a evidência irrefutável da brevidade da vida, com o aniquilamento da saúde do corpo, num movimento de fora para dentro. O cigarro já começa a representar a expressão antagônica de "estilo de vida" saudável, um aspecto fundamental da cultura tardo-moderna ${ }^{18}$. 


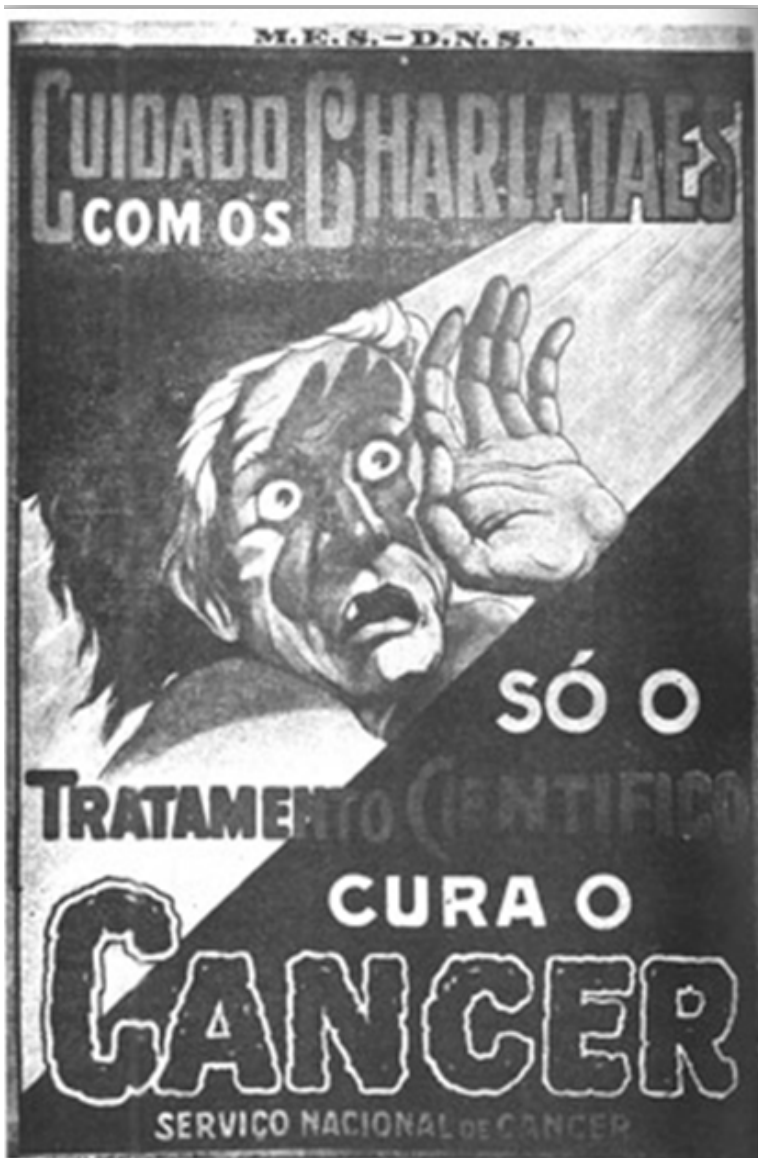

Figura 7 - Cuidado com os Charlatões Fonte: Ministério da Saúde ${ }^{13}$.

Com a publicação de informações sobre novos tratamentos para o controle do câncer em revistas científicas, a imagem do mal desconhecido passa a vir atrelada aos discursos da cura e tratamento associados à simbologia do medo, como estampa o cartaz (figura 7). Essa imagem foi publicada em 1939, junto à matéria do Jornal da Tarde do Rio de Janeiro, intitulada 'O Fumo é uma das causas do câncer que anualmente mata 20 mil pessoas no Brasil'. "O tratamento do canceroso é problema árduo porque é preciso diferenciar os pacientes [...] pelas estatísticas do Centro, observa-se que a pele é a localização mais frequente. Em segundo lugar, vem a localização da boca e vias respiratórias, atribuída ao fumo. Quanto ao fator idade, conclui-se que o câncer de boca ataca de 51 a 60 anos e o de laringe, de 41 a 50 anos. E o sexo tem predomínio do homem sobre a mulher"13.

Na conferência do médico Eduardo Rabelo, no II Congresso de Higiene, ocorrido em 1942, na cidade de Belo Horizonte, está o indicativo dessa passagem. Intitulada 'Aspecto social do problema do câncer', sua preleção revelou os números extraordinariamente elevados dos óbitos por câncer e as medidas executadas pelos governos dos Estados Unidos, Dinamarca, França e Alemanha. O aumento da mortalidade na Inglaterra levou o ministro de Saúde Pública a se ocupar de campanha patrocinada pelo Departamental Committee of Cancer, que buscava reproduzir as orientações das autoridades sanitárias quanto ao diagnóstico, terapêutica e profilaxia ${ }^{13}$.

Foi assim que o poder público e suas representações institucionalizadas centralizaram em Institutos de Medicina a investigação científica, a assistência social e a cultura profissional em suas relações com o câncer e o tabagismo. Na América do Sul, a Argentina foi o primeiro país a unificar as campanhas e propagandas com a criação da Liga Argentina Contra o Câncer.

A pesquisadora Vânia Rocha, da Casa de Oswaldo Cruz (COC), vinculada à Fiocruz, analisou materiais de campanhas educativas para prevenção e combate ao câncer no Brasil. Para ela, nesse período, as campanhas passaram por mudanças conceituais relacionadas ao câncer e exploraram novos enfoques. As ideias de 'pavor' e 
'morte anunciada', encontradas na maioria dos materiais educativos, foram, pouco a pouco, sendo substituídas por noções de que existiam recursos disponíveis e avanços no tratamento da doença. As campanhas buscaram alertar a sociedade sobre a moléstia sem, contudo, alarmar a população. A ênfase na detecção precoce ganhou força propiciada pelo progresso sobre o conhecimento da doença e pelos novos tratamentos ${ }^{19}$.

\section{A seguir, campanhas preventivas e a busca pela saúde}

Vimos até aqui que o alerta, o alarme e a advertência eram as estratégias utilizadas para chamar a atenção da população sobre a gravidade do câncer. Mas foi só a partir de 1980 que o Brasil incrementou novos modelos para as campanhas de prevenção, divulgando o maior fator de risco para o câncer de pulmão: o tabagismo. As campanhas visando à redução da prevalência de fumantes dirigidas à sociedade começam a ser definidas a partir de dados epidemiológicos e pesquisas de opinião. As linguagens das mensagens e campanhas massivas são definidas a partir do grau de exposição a determinados fatores de risco ou agentes causais ${ }^{14}$.

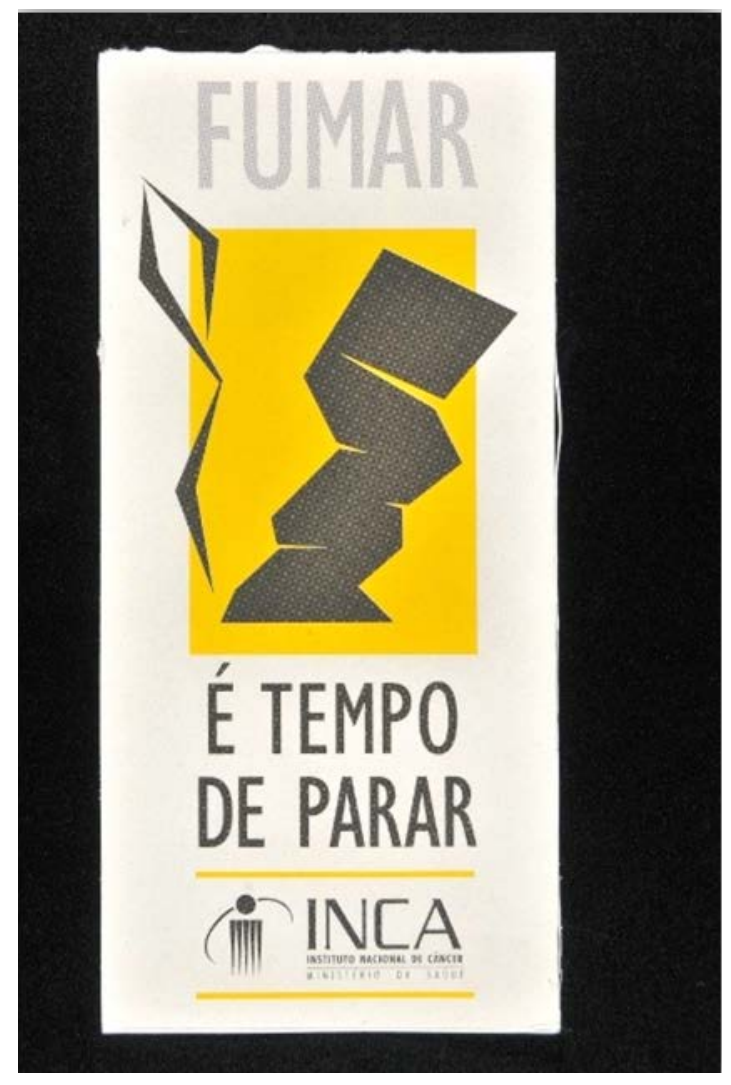

Figura 8 - Fumar. É tempo de parar Fonte: Fundação Oswaldo Cruz. ${ }^{20}$

Percorrendo o já citado acervo iconográfico da História do Câncer, é possível encontrar outros caminhos já trilhados pelas políticas públicas, com produção de imagens que apelam ao humor. O folheto informativo sobre tabagismo elaborado pelo cartunista Aroeira em 1993, a pedido do Instituto Nacional de Câncer, é o exemplo de como burlar o paradigma da doença como estrutura hedionda, do sofrimento e da dor. O slogan de lançamento da campanha foi 'Não percam as novas aventuras dos Caçadores da Saúde Perdida', uma referência ao filme Caçadores da Arca Perdida, de Steven Spielberg, sucesso de bilheteria nos anos 1980. 


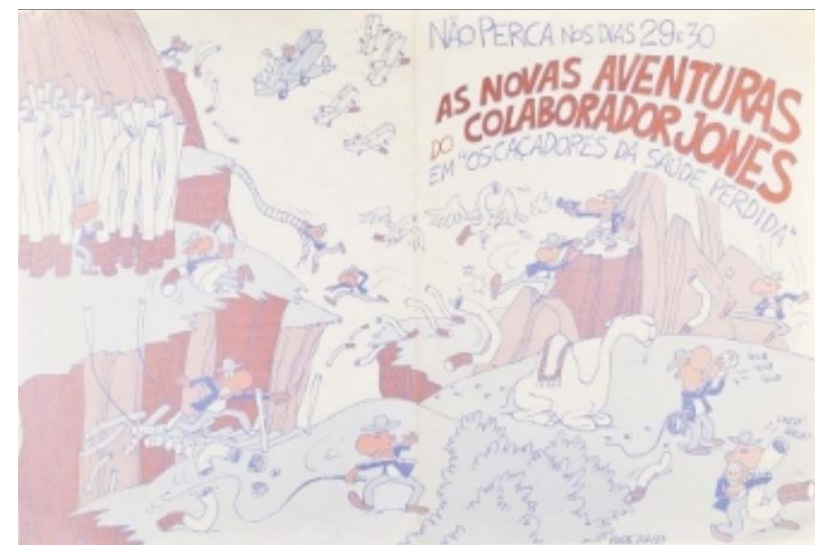

Figura 9 - Caçadores da Saúde Perdida Fonte: Fundação Oswaldo Cruz. ${ }^{20}$

De igual forma, a campanha desenvolvida pelo caricaturista Ziraldo para o Ministério da Saúde em 1996, premiada pela Organização Mundial da Saúde. Por meio do humor e do lúdico, Ziraldo apropriou-se do conhecimento popular, do senso comum, do saber prático, ressignificando o 'glamour' disseminado pela indústria, transformando-o em 'cafona', 'brega', 'careta' e 'patético'.


Figura 10 - Fumar é Brega

Fonte: Fundação Oswaldo Cruz. ${ }^{20}$

Nesse caso, os signos que dão forma concreta à comunicação junto à sociedade são usados numa abordagem positiva da saúde. O jogo muda e, em vez da perda (pelo câncer), investe-se na busca da saúde. Essa mudança em relação às estratégias da comunicação e da saúde representa uma diferença profunda no modo de pensar e propor sentidos nas mensagens e imagens veiculadas sobre o tabaco.

No final do século, as campanhas antitabagismo foram ganhando força e difundindo os benefícios conquistados com o parar de fumar e não mais os malefícios causados pelo uso do cigarro. Com a ampliação da noção de saúde para o bem-estar e com a prática de hábitos saudáveis, as campanhas passaram a refletir em seus discursos os benefícios da vida saudável. A escolha do ganho em detrimento da perda e a noção de prevenção assumem o papel de destaque na conscientização da população, mostrando que era melhor evitar a doença do que tratá-la. 

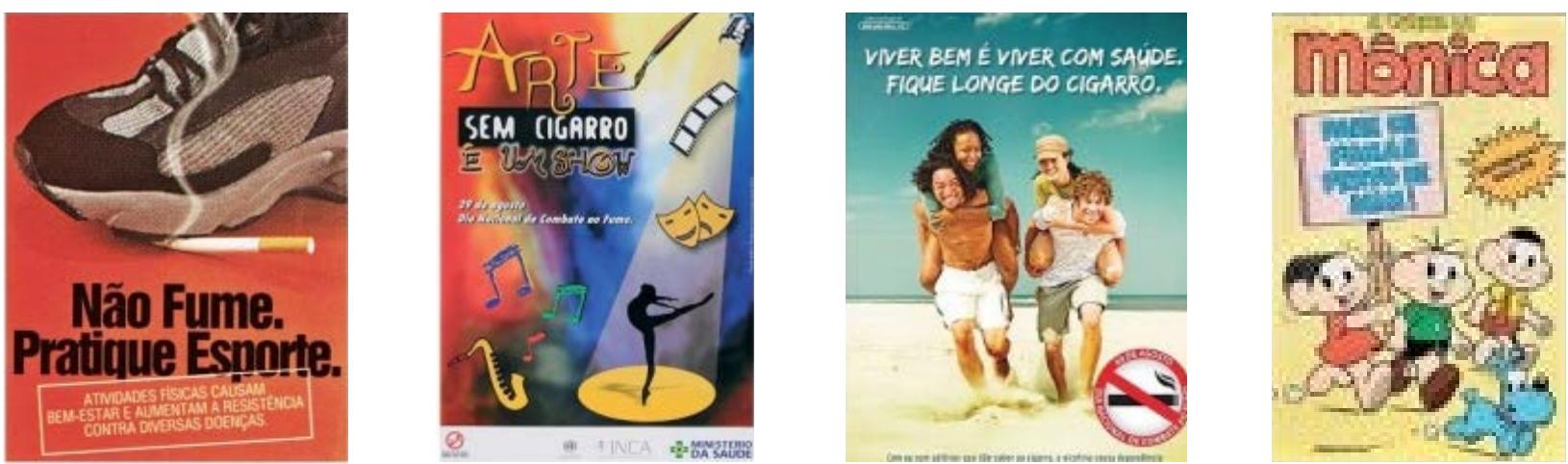

Figura 11 - Vida saudável e responsável

Fonte: Fundação Oswaldo Cruz. ${ }^{20}$

\section{Por fim, a dicotomia das práticas comunicativas}

Em 2008, o governo promoveu a campanha intitulada 'Uma juventude livre do tabaco', alertando sobre as estratégias das indústrias que estavam conquistando novos mercados principalmente onde existiam amplas vulnerabilidades coletivas. Eram nichos que podem ser seduzidos pela insuficiência de conhecimento da população sobre a realidade dos riscos do tabagismo e pela existência de representações sociais positivas relativas ao consumo de seus produtos.

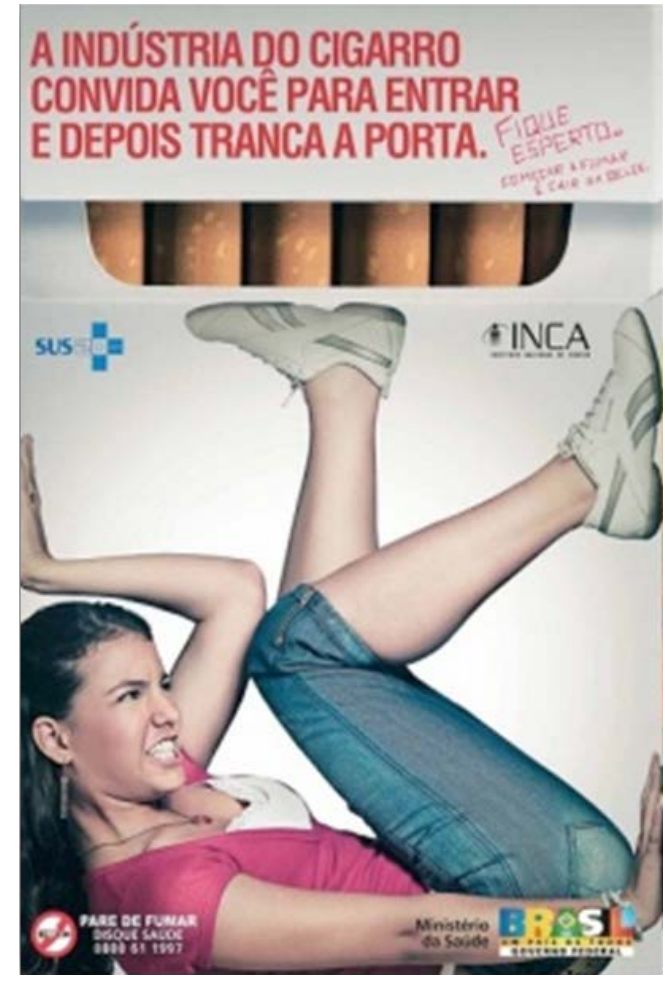

Figura 12 - A indústria do cigarro convida você para entrar e depois tranca a porta. Fique Esperto Fonte: Fundação Oswaldo Cruz. ${ }^{20}$

Naquele mesmo ano, Szklo, Coutinho, Spitz e Gamba Jr. ${ }^{21}$ realizaram estudos de intervenção pragmática utilizando grandes cartazes nas plataformas de embarque de duas estações de metrô no Rio de Janeiro. O objetivo era mostrar os efeitos adversos provocados pelo tabaco. Uma das peças associava o texto 'Fumar é perder a capacidade de respirar' à imagem de uma pessoa com dificuldade de subir as escadas. Outro cartaz ressaltava os ganhos alcançados com o ato de parar de fumar utilizando a mensagem 'Parar de fumar é ganhar capacidade de respiração' e a imagem de uma pessoa subindo as escadas sem demonstrar cansaço ou perda respiratória. 


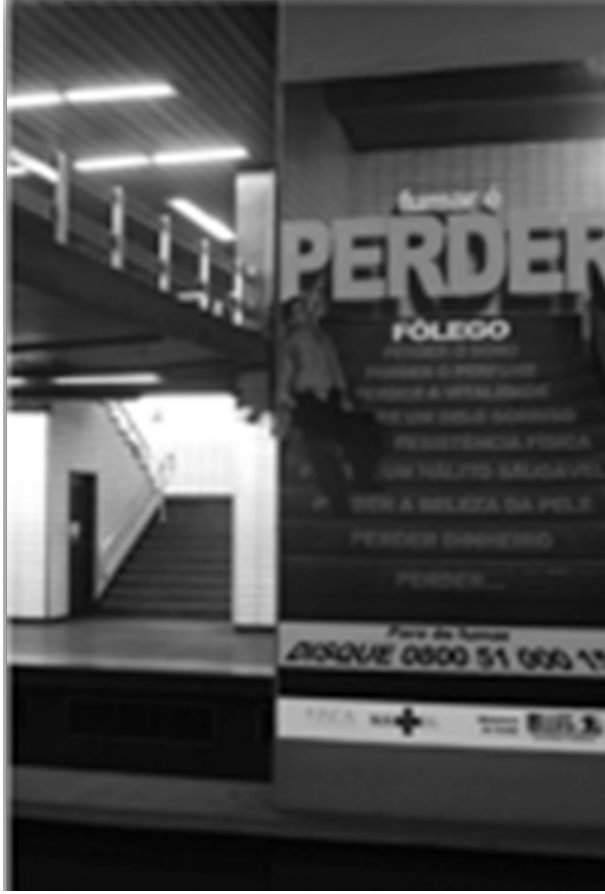

Figura 13 - Fumar é perder a capacidade de respirar Fonte: Ministério da Saúde. ${ }^{22}$

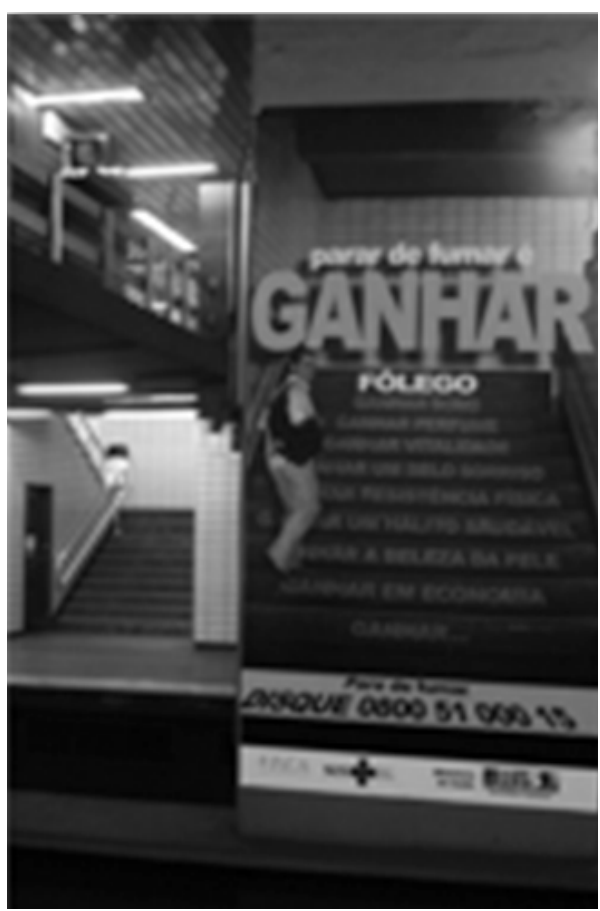

Figura 14 - Parar de fumar é ganhar capacidade de respiração Fonte: Ministério da Saúde.22

Ao final do estudo, os autores apontam: “[...] que, apesar da grande sensibilização no Brasil quanto aos malefícios do tabaco, novos formatos de comunicação abordando temas de relevância pessoal podem aumentar a quantidade e diversidade da população de fumantes recrutada para serviços de aconselhamento telefônico de suporte à cessação" ${ }^{21}$.

Em 2011, o material lançado pelo Ministério da Saúde para lembrar o Dia Nacional de Combate ao Fumo - criado em 1986 pela Lei Federal no 7.488 e celebrado em 29 de agosto - teve como tema "Viver bem é viver com saúde. Fique longe do cigarro”.

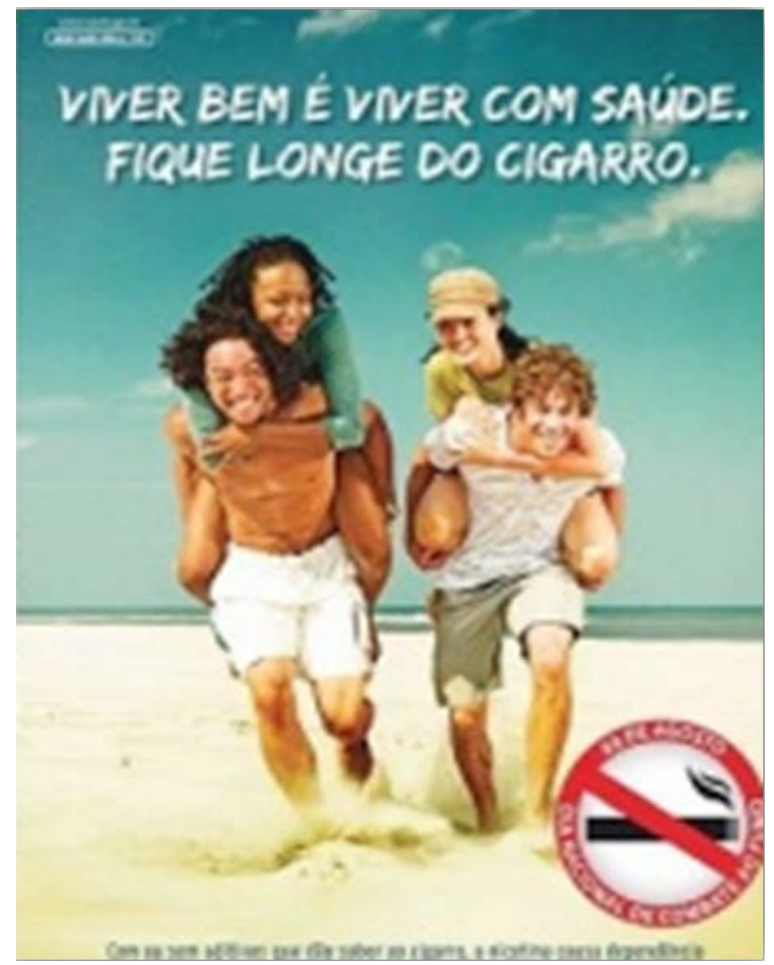

Figura 15 - Viver bem é viver com saúde. Campanha "Viver bem é viver com saúde. Fique longe do cigarro" (2011) Fonte: Fundação Oswaldo Cruz. ${ }^{20}$ 
No cartaz é clara a estratégia da campanha, que optava por focar no ganho da saúde pela ausência do hábito de fumar e não no dano provocado pelo fumo. O anúncio investe na ideia de felicidade como consequência dos hábitos saudáveis. O sentido é reforçado pelo plano visual iluminado pelo sol, pelo fundo azul, pela expressão feliz dos casais e pelo enunciado 'Viver bem é viver com saúde'. É a vida em oposição à morte. A segunda frase, no entanto, ainda reflete o tom proibitivo e autoritário da mensagem emanada do governo: 'Fique longe do cigarro'.

São muitas as interpretações e articulações que podem ser feitas com os modelos imagéticos e os conteúdos das mensagens das campanhas. Destacamos a dicotomia, a dualidade, a contradição dos percursos escolhidos pelo governo na Política de Controle do Tabaco, repercutindo em suas práticas comunicativas, que ora optam por enfatizar a saúde e os benefícios da prática de hábitos saudáveis, ora optam por enfatizar as doenças e os malefícios do tabaco. Ou, às vezes, lançam mão das duas opções ao mesmo tempo, como é o caso das peças publicitárias mostradas nas imagens 13 e 14. É importante dizer que a opção pela ênfase nas doenças e nos malefícios do tabaco foi radicalizada, a partir de 2001, nas imagens de advertência usadas nos maços de cigarros, que optaram pelo impacto da aversãoi.

\section{Saúde e doença: discussão dos riscos resultantes de escolhas}

Autores como $\mathrm{Vaz}^{23}$, Beck ${ }^{25}$, Crawford $^{26} \mathrm{e} \mathrm{Castiel}^{27}$ desenvolveram teorias dando sentido a este fenômeno de riscos resultantes de 'escolhas' no estilo de vida: saúde e doença; benefícios da prática de hábitos saudáveis e malefícios do tabaco. Ao longo dos anos, várias foram as tentativas de ordem teórica e conceitual de definição dessa categoria do estilo de vida que comporta uma variedade de sentidos.

Desde os anos 1970, ganha destaque a noção de que estilos saudáveis promovem melhor qualidade de vida, tendo como referência a inclusão de duas classes de fatores: socioambientais (trabalho, educação, saúde etc.) e individuais (característicos do comportamento de cada cidadão), estabelecendo, assim, uma relação causal entre estilo de vida e determinantes sociais de saúde. Nesse sentido, os elementos nocivos à saúde promovem riscos e, para disseminar e informar a sociedade sobre a dimensão desses riscos, o Estado brasileiro utiliza várias estratégias e ferramentas de comunicação para a política antitabagista.

Este cenário resultou na entidade da vigília moral criada em torno do tabaco. Parte-se do primeiro contato do indivíduo com o objeto, depois, a inalação, o prazer, até o momento em que ele adquire o hábito de fumar, o vício, transpondo a condição de ser saudável para o ser doente, atingido pelo 'tabagismo'. Segundo Freire Filho e Vaz, "é criado um estado de 'quase-doença' generalizado: mesmo não sentindo nenhuma limitação no presente e diante de oportunidades de prazer, todo e qualquer indivíduo deve alterar seu estilo de vida dada a possibilidade de adoecer no futuro" ${ }^{24}$.

Há que se refletir sobre que tipo de vida está sendo construída por esses alertas sobre perigos que estariam à espreita em nossos hábitos e que podem se concretizar no futuro. Para Vaz, "as informações sobre risco influenciam na edificação da moralidade dominante na cultura atual”" ${ }^{3}$. Essa reflexão é reforçada por Castiel, quando afirma que é "inevitável a associação de 'responsabilidade' com 'culpa', especialmente no que se refere aos descumprimentos de obrigações”" ${ }^{27}$. Responsabilização, verdades, culpa, individualização, moral, são expressões que concorrem na sociedade onde a ciência estipula os riscos, e a população percebe os riscos ${ }^{25}$.

Doença é ausência de saúde, aí reside o paradoxo refletido nas campanhas publicitárias antitabagistas. Para Freire Filho e Vaz, "a morte está sempre por vir, podendo seu advento ser adiado por meio de escolhas, cientificamente fundadas, do indivíduo em relação a seu estilo de vida" ${ }^{24}$. Para o autor "o discurso estabelece a possibilidade de uma distinção social: não entre agressores e vítimas, mas entre quem sabe e quem não sabe cuidar de si” ${ }^{24}$.

i Sobre o assunto, ver: Ruas ECM. As advertências sanitárias na prevenção do tabagismo: um estudo semiológico [dissertação de mestrado]. Rio de Janeiro: Fundação Oswaldo Cruz; 2013. 
A produção das campanhas antitabagistas de governo é mais uma tentativa de corroborar essa comunhão de ameaças, com apelo à sensação do medo e da culpa do indivíduo, que marcam uma intercessão seminal na história do tabagismo.

Neste contexto, existe uma relação entre as abordagens que converge para o que Crawford ${ }^{26}$ denominou "culpabilização da vítima”, quando se responsabiliza o indivíduo por suas ações e condição de vida, tratando como fenômeno individual, descontextualizado das manifestações sociais, políticas, culturais e econômicas. A associação entre os fenômenos de "medicalização do cotidiano social" e de "culpabilização da vítima" culmina no que Crawford chama de "salutarismo" (healthism). "A expressão é usada para criticar a noção de que o indivíduo é o único responsável pela saúde e, portanto, por adotar comportamentos considerados 'não saudáveis"”26.

São modelos teóricos do campo da saúde que ativam a necessidade de união de todos contra um inimigo comum. Este movimento de culpabilizar o indivíduo, "reduz a responsabilidade das instituições do seu papel de transformar as condições de saúde da população, turvando as diferenças sociais, culturais e econômicas”²7.

As campanhas antitabagistas passam a ser uma medida reconhecida socialmente e cientificamente, um meio de comunicação para informar a sociedade sobre os riscos do tabagismo e um potencial canal de comunicação dessa vigília moral, um complexo processo de negociação que envolve governo, indústria e sociedade, numa prática comunicativa eminentemente ligada à cidadania, aos direitos do consumidor e à responsabilidade civil.

\section{Considerações finais}

$\mathrm{Na}$ leitura dos documentos que narram a história imagética das campanhas educativas de controle do tabagismo, começamos a análise com as primeiras, a partir dos anos 1940. Evidenciou-se ali o uso do argumento sanitário das evidências associando o tabagismo ao risco, produzindo mensagens que procuravam incutir na consciência pública a hipérbole da proteção, culpando o fumante em si mesmo e dentro do corpo social por meio de imagens que expressavam sentidos de terror, medo e morte, com perda da saúde. Um alarmismo reverberado pelas mídias e autoridades da saúde.

Na sequência, já nos anos de 1960, o alarde público que influenciou as campanhas antitabagistas ainda reforçava o medo, mas somava-se o diagnóstico e o tratamento que eliminavam a doença, contribuindo para criar um ambiente social que enfatizava a visão curativa. A partir dos anos 1980, associado ao debate do estilo de vida ativo como estratégia de saúde pública, tornou-se consenso que estilos de vida saudáveis promovem mais qualidade de vida. Isso cria uma mudança de paradigma nas campanhas do governo. As narrativas de perda da saúde começam a dar lugar ao ganho de qualidade de vida com a cessação do hábito de fumar. As campanhas como canal de comunicação mediador entre o campo da saúde e a sociedade iniciam um processo de aconselhamento em direção à prevenção e promoção da saúde como modo de evitar doenças.

$\mathrm{O}$ argumento sanitário da evidência científica associou o tabagismo a risco no âmbito da vida social. Estabeleceram, assim, uma relação causal entre estilo de vida e determinantes sociais de saúde. Nesse sentido, os elementos nocivos à saúde promovem riscos e, para disseminar e informar a sociedade sobre a dimensão desses riscos, o Estado brasileiro utiliza várias estratégias e ferramentas de comunicação para a política antitabagista.

Foi criada em torno do tabaco a entidade da vigília moral, porém, informar sobre os riscos não significa reforçar o conceito de vigília moral. Acreditamos na via mais próxima dos princípios doutrinários do Sistema Único de Saúde, da concepção dialógica e plural da comunicação.

\section{Referências}

1. Lasswell HD. Propaganda technique in the World War. New York: Peter Smith; 1927.

2. $\quad$ Pinho JB. O poder das marcas. São Paulo: Summus Editorial; 1996. 
3. Multi-midia [Internet]. 2000-2008 [citado em 2006 maio 11]. Disponível em: www2.gol.com/users/ sergiok/media.htm.

4. Rodriguez AS. Cinema clássico americano e produção de subjetividades: o cigarro em cena. (Dissertação de mestrado). Florianópolis: Universidade Federal de Santa Catarina; 2008.

5. $\quad$ Cigarros Hollywood. O Cruzeiro (Diários Associados). 7 maio 1949:47.

6. The Sun. Marlboro man, pin up from the 1970s, dies after a lifetime of smoking. London: News Group Newspapers Limited; 2014 [citado em 2018 out. 29]. Disponível em: http://www.thesun.co.uk/sol/ homepage/news/5403923/marlboro-man-pin-up-from-1970s-dies-after-lifetime-of-smoking.html.

7. Carneiro $\mathrm{H}$. As necessidades humanas e o proibicionismo das drogas no Século XX. Outubro. 2002;6(2):115-128.

8. Wynder EL, Graham EA. Tobacco smoking as a possible etiologic factor in bronchiogenic carcinoma. J Am Med Assoc. 1950;143(4):329-336.

9. Doll $\mathrm{R}$, Hill $A B$. The mortality of doctors in relation to their smoking habits; a preliminary report. Br Med J. 1954;1(4877):1451-1455.

10. Ferlay J, Steliarova-Foucher E, Lortet-Tieulent J, Rosso S, Coebergh JWW, Comber H et al. Cancer incidence and mortality patterns in Europe: estimates for 40 countries. Eur ] Cancer [Internet]. 2013 [citado em 2013 fev. 26]; 49(6):1374-403. Disponível em: https://www.ncbi.nlm.nih.gov/ pubmed/23485231. doi: https://doi.org/10.1016/j.ejca.2012.12.027.

11. Siddhartha M. O imperador de todos os males: uma biografia do câncer. São Paulo: Companhia das Letras; 2012.

12. World Health Organization. WHO report on the global tobacco epidemic, 2013: enforcing bans on tobacco advertising, promotion and sponsorship [Internet]. Geneva: WHO; 2013 [citado em 2018 maio 15]. Disponível em: http://apps.who.int/iris/bitstream/10665/85380/1/9789241505871 eng.pdf?ua=1.

13. Ministério da Saúde (BR). Instituto Nacional de Câncer. Resenha da luta contra o câncer no Brasil: documentário do Serviço Nacional de Câncer. 2 ed. Brasília, DF: Ministério da Saúde; 2007.

14. Pitta RMA. Saúde \& comunicação: visibilidades e silêncios. São Paulo: Hucitec; 1995.

15. Araujo IS, Cardoso JM. Comunicação e saúde. Rio de Janeiro: Ed. Fiocruz; 2007.

16. Mattelart A, Mattelart M. História das teorias da comunicação. São Paulo: Loyola; 1999.

17. Teixeira LA, Jaques TA. Legislação e controle do tabaco no brasil entre o final do século XX e início do XXI. Revista Brasileira de Cancerologia. 2011;57(3):295-304.

18. Giddens A. As consequências da modernidade. Oeiras: Celta; 1990.

19. Rocha V. Do caranguejo vermelho ao Cristo cor-de-rosa: as campanhas educativas para a prevenção do câncer no Brasil. Hist. cienc. saude-Manguinhos. 2010;17(supl. 1):253-263.

20. Fundação Oswaldo Cruz, Casa de Oswaldo Cruz. Acervo de imagens [Internet]. Rio de Janeiro: Casa de Oswlado Cruz; [citado em 2015 dez. 04]. Disponível em: http://goo.gl/Zxukvj.

21. Szklo AS, Coutinho ESF, Barros HMT, Perez C, Moreira TC et al. Estratégia de recrutamento de fumantes no metrô do Rio de Janeiro, Brasil, para ampliar o acesso a linhas telefônicas de apoio à cessação: impacto da novidade. Cad. Saúde Pública. 2009;25(11):2524-2528.

22. Szklo AS, Coutinho ESF, Spitz R, Gamba Jr N. Gains of stopping smoking: portraits ofthe dialogue between public health promotion, art and design. Int J Epidemiol. 2009:38(6):1459-1463. doi: https:// doi.org/10.1093/ije/dyp251.

23. Vaz P. As narrativas midiáticas sobre os cuidados com a saúde e a construção de subjetividade contemporânea. Logos. 2006 [citado em 2012 jul. 09]:25(1):50-75. Disponível em: http://www.logos. uerj.br/PDFS/25/08_Paulo_Vaz.pdf.

24. Freire Filho J, Vaz P, organizadores. Construções do tempo e do outro: representações e discursos midiáticos sobre alteridade. Rio de Janeiro: Mauad X; 2007. p. 15-16.

25. Beck U. Sociedade de risco, rumo a uma outra modernidade. São Paulo: Editora 34; 2010.

26. Crawford R. Health as a meaningful social practice. Health. 2006:10(4):401-420. 